\title{
PROJETO DIDÁTICO DE GÊNERO E PRODUÇÃO TEXTUAL ESCRITA: UM ESTUDO DE CASO A PARTIR DO TRABALHO COM O GÊNERO “CARTA DE RECLAMAÇÃo”
}

\author{
GENRE EDUCATION PROJECT AND WRITTEN TEXTUAL PRODUCTION: \\ A CASE STUDY FROM THE WORK WITH THE GENRE \\ "LETTER OF COMPLAINT"
}
Caroline Gomes Motta ${ }^{1}$ Lattes | caroline.mottag@gmail.com Universidade do Vale do Rio dos Sinos
Anderson Carnin ${ }^{2}$ Lattes | anderson.carnin@gmail.com Universidade do Vale do Rio dos Sinos

Resumo: Este artigo analisa o desenvolvimento da produção textual de um aluno de $6^{\circ}$ ano do Ensino Fundamental a partir da interação/intervenção docente realizada durante o desenvolvimento de um projeto didático de gênero voltado ao trabalho com o gênero "carta de reclamação". Com base no marco teórico do Interacionismo Sociodiscursivo, investigamos traços do trabalho docente materializados na correção e na avaliação das produções textuais e seu(s) impacto(s) no desenvolvimento da (re)escrita discente. Os resultados obtidos sugerem que a grade de avaliação possui maior influência nas produções textuais que o trabalho de correção textual-interativa, isto é, as intervenções da professora nos textos.

Palavras-chave: Produção textual. Carta de reclamação. Projeto didático de gênero. Interacionismo Sociodiscursivo.

Abstract: This article analyzes the development of the textual production of a 6th grade elementary student from the interaction / teaching intervention carried out during the development of a genre education project aimed at teaching the genre "letter of complaint”. Based on the theoretical framework of Sociodiscursive Interactionism, we inves-

\footnotetext{
${ }^{1}$ Mestra em Linguística Aplicada pelo Programa de Pós-Graduação em Linguística Aplicada da Unisinos. (Bolsista CAPES Processo no 88887.179228/2018-00).

2 Doutor em Linguística Aplicada. Professor do Programa de Pós-Graduação em Linguística Aplicada da Unisinos.
} 
tigate traces of the teaching work materialized in the correction and assessment of textual productions and their impact(s) in the development of student (re)writing. The results obtained suggest that the assessment chart has a greater influence on textual productions than textual-interactive correction work, that is, the teacher's interventions in texts.

Keywords: Textual production. Letter of complaint. Genre education project. Sociodiscursive Interactionism.

\section{Considerações iniciais}

Não é novidade que o ensino da escrita a partir do trabalho com gêneros de texto/ discurso diversos em sala de aula é um princípio norteador do trabalho do professor de Língua Portuguesa, em qualquer nível de ensino. Diferentes documentos oficiais (e. $g$. BRASIL, 1998, 2018; RIO GRANDE DO SUL, 2009) reiteram essa perspectiva, ratificando que o objeto central da aula de língua materna, em contexto escolar, deve ser o ensino baseado em gêneros de texto/discurso, com vistas ao desenvolvimento de múltiplos letramentos dos nossos estudantes. Tal perspectiva, que continua atual e constitui-se em fértil terreno de discussões teóricas, metodológicas e em práticas de ensino voltadas à sua instauração didática, procura atribuir ao ensino da escrita (e também da leitura, oralidade e análise linguística) papel central na formação de nossos educandos. Diante dessas discussões, consoante Dolz, Gagnon e Decândio (2010), entendemos que a aprendizagem da escrita se constitui como uma finalidade central no ensino de língua materna. Na esteira de outras pesquisas realizadas sobre essa temática (PEREIRA; CARDOSO, 2013; JORDÃO; NONATO, 2018; PEREIRA; BEZERRA, 2018), este artigo procura lançar luz sobre o processo de desenvolvimento da produção textual de um aluno de uma turma de $6^{\circ}$ ano do Ensino Fundamental, tendo em vista as interações/intervenções realizadas por uma professora ao trabalhar com o gênero carta de reclamação durante o desenvolvimento de um projeto didático de gênero - PDG - (GUIMARÃES; KERSCH, 2012, 2014; GUIMARÃES; CARNIN; KERSCH, 2015) em uma escola do município de Novo Hamburgo (RS), cuja professora participou de cursos de formação continuada desenvolvidos por nosso grupo de pesquisa ${ }^{3}$. O objetivo deste artigo, pois, consiste em investigar

\footnotetext{
${ }^{3}$ Referimo-nos aos cursos de extensão "Caminhos da Construção: projetos didáticos de gênero na sala de aula de Língua Portuguesa", vinculados ao projeto de pesquisa "Por uma formação continuada cooperativa para o desenvolvimento dos processos educativos de leitura e produção textual escrita”, realizados com apoio da Capes/Inep (Programa Observatório da Educação, edital 028/2010) entre os anos de 2010 a 2014.
} 
traços de desenvolvimento da escrita, especificamente da argumentação, na produção do gênero carta de reclamação por um estudante do Ensino Fundamental, além de analisar como o trabalho docente impacta nesse desenvolvimento, a partir das correções desenvolvidas pela professora nas produções textuais deste discente. A opção pelo estudo de caso, neste artigo, decorre do fato de que queremos elucidar com mais profundidade o impacto do trabalho docente na produção escrita discente, considerando, especialmente, que se trata de um trabalho de ensino não controlado pelos pesquisadores, mas sim de uma análise explicativa do fenômeno observado.

Para cumprir tal propósito, este texto está organizado do seguinte modo: nas duas seções seguintes, embasados principalmente no marco teórico do Interacionismo Sociodiscursivo (BRONCKART, 1999, 2006, 2008), apresentaremos nossas reflexões sobre o ensino da escrita e sobre projetos didáticos de gênero, resgatando também as noções de trabalho real e trabalho prescrito, basilares para este estudo. Em seguida, detalharemos a metodologia empregada na pesquisa aqui apresentada. A seção de análise está dividida em duas etapas: primeiramente, analisamos as produções finais de duas estudantes, observando o trabalho da professora com as correções dos textos; após, a fim de aprofundar nossas discussões, analisamos, mais detidamente, como a professora conduziu um dos estudantes da turma à reescrita e à versão final, considerando também a grade de avaliação que orientou esse trabalho, a fim de analisar se houve impacto no desenvolvimento do texto do aluno, principalmente no que se refere à habilidade de argumentação, constitutiva do gênero estudado. A última seção encerra este estudo apresentando as considerações que foram tecidas a partir desta pesquisa e as perspectivas que delas se desdobram.

\section{Sobre o Interacionismo Sociodiscursivo: a centralidade do conceito de gênero de texto e o trabalho (de ensino) do professor}

Assumimos, neste artigo, o Interacionismo Sociodiscursivo (ISD) como marco teórico-metodológico que embasa nossas reflexões. Para Bronckart (2006, p. 153), principal epistemólogo do ISD, "uma das teses centrais do Interacionismo Sociodiscursivo é a de que a prática (na produção e na recepção/interpretação) dos gêneros de textos e dos tipos de discurso é a principal ocasião de desenvolvimento de mediações formativas". Ou seja: o autor atribui papel central à interação verbal mediada pelos gêneros de texto - seja em contextos de ensino ou para além deles - e acentua, também, o papel dos tipos de discurso como recurso linguístico-discursivo que potencializa o desenvolvimento dos sujeitos que se engajam em práticas discursivas as mais diversas. 
Como neste trabalho nos interessa explorar tal premissa em contexto(s) de ensino da escrita em aulas de língua portuguesa, propomo-nos refletir sobre tal questão, correlacionando-a ao trabalho de ensino do professor. Nesse sentido, esta seção retoma, num primeiro momento, a centralidade do conceito de gênero de texto para o quadro do ISD, bem como discute a configuração dos tipos de discurso propostos por Bronckart (1999) para, em seguida, resgatar proposições importantes sobre o trabalho do professor discutidas no âmbito desse mesmo marco teórico.

\subsection{Da noção de gênero de texto e de tipos de discurso}

O conceito de gênero discursivo como a cristalização de "[...] tipos relativamente estáveis de enunciados" proposta por Bakhtin (2003, p. 279) abarca em seu escopo aspectos tanto enunciativos quanto discursivos. Deslocada de seu espaço de reflexão original (a filosofia da linguagem/estudos literários), o conceito bakhtiniano de gêneros discursivos, quando realocado em um espaço de reflexão pedagógica, permite, de acordo com Barbosa (2000, p. 152-153, grifos da autora), “[...] incorporar elementos da ordem do social e do histórico; permite considerar a situação de produção de um dado discurso, abrange o conteúdo temático, a construção composicional e seu estilo verbal".

Nesse sentido, a eleição do texto como unidade básica para o ensino de língua(gem) e do conceito exposto de gênero discursivo como articulador do trabalho a ser realizado em sala de aula representa, sem dúvida, a grande inovação que as propostas oficiais de ensino e de aprendizagem de português empreenderam, especialmente nas duas últimas décadas (BRASIL, 1998, 2018; RIO GRANDE DO SUL, 2009).

Ao constatar que, apesar de muito produtivo e epistemologicamente coerente, esse conceito não pode ser transposto diretamente à sala de aula, ao trabalho didático com a língua(gem), diversos estudiosos, mais especificamente da subárea da didática da língua(gem), enfrentaram o desafio de propor reflexões que sustentassem a adoção de tal conceito principalmente no espaço do trabalho escolar. Como resultado dessa preocupação, diferentes propostas de trabalho com gêneros - ainda fruto de uma releitura da obra bakhtiniana - foram sendo desenvolvidas tanto no Brasil quanto no mundo. A mais conhecida delas, pelo menos em nosso país, é, possivelmente, a proposta de trabalho derivada da corrente teórica do Interacionismo Sociodiscursivo, inaugurada por Jean-Paul Bronckart, juntamente com Bernard Schneuwly, na Universidade de Genebra na década de 1980. 
Tal corrente, que, em sua gênese, leva em consideração postulados dos estudos de Vigotski, de Saussure e, claro, de Voloshinov/Bakhtin, tem como (pre)ocupação maior o estudo do papel nodal da linguagem na ontogênese humana. A partir de uma grande pesquisa acerca do funcionamento dos textos/discursos, propôs um conceito de gênero de texto muito próximo do conceito bakhtiniano de gênero do discurso. Bronckart (1999, p. 101-102) define, à semelhança de Bakhtin, “[...] gênero de texto como tipos relativamente estáveis de enunciados, elaborados sócio-historicamente, por diferentes esferas das atividades humanas, sempre apresentando conteúdo, estruturação, relação entre os interlocutores e estilo específicos”.

Uma das grandes particularidades do marco teórico do Interacionismo Sociodiscursivo é a compreensão teórica de que os gêneros de texto comportam em sua composição diferentes tipos de discurso, isto é, “[...] formas linguísticas que são identificáveis nos textos e que traduzem a criação de mundos discursivos específicos articulados entre si por mecanismos de textualização e mecanismos enunciativos” (BRONCKART, 1999, p. 149). Segundo Bronckart (2008, p. 87), essa especificidade se deve à compreensão de que "[...] o termo discurso designa a atualização da linguagem por indivíduos em situações concretas" e se associa "[...] às formas de realização das operações do pensamento humano (contar, conversar, argumentar, teorizar), o que mostra a dimensão cognitiva ou epistêmica desse sistema" (BRONCKART, 2008, p. 40). Na esteira dessa discussão, Bronckart (1999) esclarece que os gêneros de texto podem apresentar quatro tipos de discurso ${ }^{4}$ (discurso interativo, discurso teórico, relato interativo e narração), os quais se relacionam a mundos discursivos conjuntos (ancorados ao momento da enunciação) ou disjuntos (relacionados a um tempo anterior ao momento da enunciação) e à implicação ou à autonomia de quem enuncia em seu discurso. O Quadro 1, a seguir, adaptado de Bronckart (1999), possibilita melhor identificar os quatro tipos de discurso e a conjuntura discursiva que os particularizam:

\footnotetext{
${ }^{4}$ A classificação dos tipos de discurso entre os quatro principais reconhecidos por Bronckart $(1999,2008)$ não implica uma absolutização dessa classificação. O próprio autor admite que variantes na situação de produção, nos próprios tipos e entre as fronteiras entre os tipos discursivos são alvo de constante reformulação, possibilitando a formação e o reconhecimento de tipos mistos de discurso. Assim, Bronckart (1999) prevê a existência, por exemplo, de um tipo de discurso interativo teórico-misto, entre outras possibilidades.
} 


\begin{tabular}{|c|c|c|}
\hline & $\begin{array}{l}\text { Conjunção com o mundo } \\
\text { real } \\
\text { EXPOR }\end{array}$ & $\begin{array}{l}\begin{array}{l}\text { Disjunção com o } \\
\text { mundo real }\end{array} \\
\text { NARRAR }\end{array}$ \\
\hline $\begin{array}{l}\text { Implicação em relação ao } \\
\text { ato de produção }\end{array}$ & 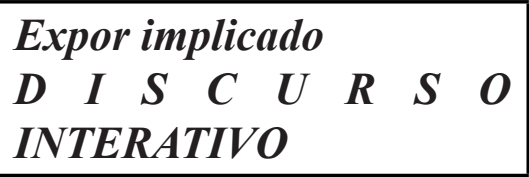 & 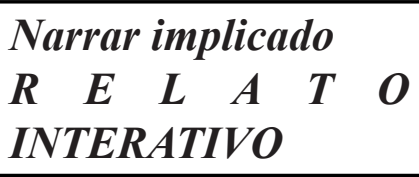 \\
\hline $\begin{array}{l}\text { Não-implicação/ autono- } \\
\text { mia em relação ao ato de } \\
\text { produção }\end{array}$ & $\begin{array}{l}\text { Expor autônomo } \\
\text { DISCURSO TEÓRICO }\end{array}$ & $\begin{array}{l}\text { Narrar autônomo } \\
\text { NARRAÇÃO }\end{array}$ \\
\hline
\end{tabular}

Fonte: Adaptado de Bronckart (1999).

Para uma melhor compreensão dos tipos de discurso, é interessante elencar algumas características que singularizam cada um deles. No discurso interativo, são encontradas formas verbais que implicam pelo menos um dos participantes da interação, dêiticos temporais e espaciais e tempos verbais que colocam as ações verbalizadas como concomitantes ao momento de produção.

No relato interativo, percebemos a presença de elementos linguísticos que implicam os participantes da interação no texto produzido, mas, diferentemente do discurso interativo, os fatos narrados estão distantes temporalmente do momento de produção.

Por sua vez, o discurso teórico não apresenta marcas que remetam ao participante da interação. Nota-se presença do presente genérico, de nominalizações e os conteúdos expressos são colocados de modo conjunto ao momento da produção.

Por fim, a narração não apresenta marcas que remetam à situação de produção textual e, além disso, há referência a um tempo passado, disjunto da situação de produção.

Em síntese, cumpre reforçar que os tipos de discurso, na perspectiva do Interacionismo Sociodiscursivo, são configurações linguístico-textuais que semiotizam um posicionamento enunciativo do produtor dos textos, de modo que o seu emprego como unidade de análise poderá nos fornecer pistas sobre o impacto do trabalho do professor sobre as aprendizagens discentes. 


\subsection{Da noção de trabalho do professor}

Consoante Bronckart (2006, 2008), a noção de trabalho está associada a uma forma de agir no mundo e transformar a realidade. Para o epistemólogo, há três dimensões analíticas do trabalho: o real, o prescrito e o representado. Especificamente para este estudo, nosso foco se volta às dimensões do trabalho real e do trabalho prescrito. Vale lembrar que no âmbito do ISD o trabalho real refere-se às interações entre o professor e seus alunos, tendo em vista a capacidade do professor de pilotar a sala de aula e conduzir seu projeto didático. $\mathrm{O}$ trabalho prescrito refere-se especialmente aos documentos norteadores e reguladores do ensino, mas também às próprias (auto)prescrições que o professor produz para orientar seu próprio agir (e.g.: planos de aula, atividades de ensino, etc.). O trabalho representado emerge, por exemplo, em situações de interação e/ou pesquisa, em que o trabalhador é levado a falar sobre os modos como percebe seu trabalho, fazendo emergir as representações que ele possui sobre isso.

Da dimensão do trabalho real, enfocaremos neste artigo o(s) modo(s) como a professora que colaborou com esta pesquisa conduziu seu trabalho de ensinar a escrever, pilotando seu projeto de ensino, enfocando, pelos limites deste texto, a sua intervenção/correção nas versões do texto de um aluno. Chamaremos esse tipo de trabalho de "real assíncrono", uma vez que a interação não ocorre de forma face a face, pois a professora avalia o texto e faz suas observações em um momento anterior à leitura dessa avaliação pela estudante. A grade de avaliação, que também é objeto de análise deste estudo, constitui-se, a nosso ver, como uma prescrição proposta pela própria professo$\mathrm{ra}^{5}$ para o seu trabalho de avaliação das produções textuais, pois, conforme Bronckart (2006, p. 208) a prescrição “[...] constitui-se como uma representação do que deve ser o trabalho, que é anterior à sua realização efetiva”. Ou seja: tem-se, aqui, a evidente tensão entre o trabalho (auto)prescrito da professora para a avaliação das produções textuais de seus alunos e o trabalho real, materializado nas interações/intervenções deixadas/produzidas na leitura/avaliação dos textos de seus estudantes. Interessa-nos, pois, observar como essa tensão produz efeitos também na aprendizagem discente do gênero "carta de reclamação".

\footnotetext{
${ }^{5}$ Cabe ressaltar que a proposta dos projetos didáticos de gênero em relação à grade de avaliação é de que ela seja elaborada em conjunto com os alunos, com base nas oficinas de estudo do gênero de texto e da prática social relacionada, estabelecendo um "contrato didático" entre a professora e a turma que estipula os critérios para a escrita do texto.
} 


\section{Do ensino da escrita: princípios norteadores do trabalho com projetos didáticos de gênero}

Assumimos, junto a Dolz, Gagnon e Decândio (2010), que o ensino de produção escrita que pretende trabalhar com essa competência no quadro da comunicação social mais ampla deve ter como objeto de ensino o gênero de texto. Além de destacar que o ensino da produção textual escrita deva acontecer a partir de gêneros de texto, Dolz, Gagnon e Decândio (2010) adicionam a essa problemática de estudo que os professores, ao desenvolver aulas voltadas para o ensino da produção escrita, devem considerar que esse objeto de ensino é uma atividade complexa, aprendida a partir "de um processo de construção em diversas situações complexas de comunicação" (DOLZ; GAGNON; DECÂNDIO, 2010, p. 18) e que essa competência é aprendida progressivamente em todos os níveis de escolaridade. Portanto, não basta ensinar questões gramaticais descontextualizadas e "dicas" para escrever bem, deve-se considerar que a escrita de um texto faz parte de um processo mais amplo de interação social, sempre ancorada na produção de textos pertencentes a um determinado gênero de texto. Esse, contudo, não parecia ser o entendimento dos 45 professores que participaram do projeto de pesquisa que dá origem a este texto. Quando indagados, em formulário de sondagem aplicado antes do início do projeto de pesquisa, sobre o que poderia ser classificado como gênero de texto, dentre as opções abaixo, muitos de nossos colaboradores de pesquisa confundiram, por exemplo, narração (tipologia textual) ou mesmo jornal (suporte) com gênero de texto.

Gráfico 1 - Classificando "gêneros de texto".

18) Você classificaria como gênero de texto (mais de uma opção pode ser assinalada):

43 respostas

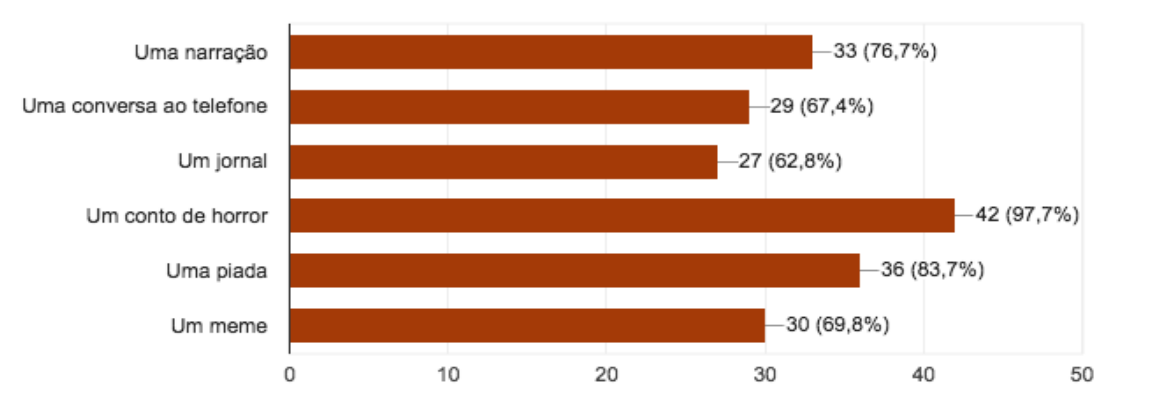

Fonte: Acervo do Projeto "Por uma formação continuada cooperativa para o desenvolvimento de leitura e produção textual escrita no Ensino Fundamental”.

Tal confusão nos deu um ponto de partida. Era essencial resgatarmos junto ao coletivo de professores a noção de gênero de texto e as formas de transposição didática desse conhecimento ao contexto escolar. Considerando essa necessidade, a proposta formativa de- 
senvolvida pelo grupo de pesquisa envolveu a construção de um coletivo de pesquisadores e professores atuantes na Educação Básica organizados em torno de um problema central: como ressignificar as práticas de leitura e escrita dos estudantes (e, articulado a isso, as práticas de ensino dos professores) para atingir resultados mais satisfatórios na aprendizagem dessas competências? Assim, na articulação dos diferentes saberes docentes que eram trazidos à discussão e ressignificados pelo coletivo de trabalho que o projeto de pesquisa permitiu construir é que emergiu, a partir de uma construção conjunta, a proposta de organização do trabalho pedagógico intitulada de projeto didático de gênero - PDG - (GUIMARÃES; KERSCH, 2012). Nessa proposta, que parte da conhecida noção de sequência didática (SCHNEUWLY; DOLZ, 2004), influências advindas dos estudos do letramento - como os projetos de letramento, que podem ser vistos em Kleiman (2000) e Tinoco (2008) levaram o grupo a propor que práticas de leitura fossem incorporadas ao lado das práticas de produção textual das sequências didáticas. Assim, compreendidas na perspectiva dos estudos de letramento, as práticas de leitura e escrita que compõem um projeto didático de gênero emergem (ou devem emergir) de outras práticas sociais da comunidade em que os alunos estão inseridos, para, a partir delas, ir além no desenvolvimento das competências de leitura e escrita dos estudantes. Com esse objetivo, o projeto didático de gênero serve como um termo guarda-chuva que abriga, em seu escopo, um trabalho didático de ensino da língua materna que quer, sim, que o aluno domine o(s) gênero(s) de texto estudado(s), mas que também tenha, à semelhança dos projetos de letramento, um produto, um resultado a partir do qual os alunos consigam se engajar qualificadamente em uma prática social autêntica, na qual o domínio do(s) gênero(s) pode proporcionar maior participação social.

Para além de articular duas tradições de pesquisa (o Interacionismo Sociodiscursivo e os estudos de letramento), vale ressaltar que:

um projeto didático de gênero (PDG) é uma proposta metodológica de didatização de gêneros. Traz como diferencial o fato de ser um projeto, voltado, portanto, para uma sequência de atividades que se realizarão dentro e fora da escola, de forma a garantir que o(s) gênero(s) tratado(s) esteja $(\mathrm{m})$ realmente ligados a uma prática social. Tal prática pode se dar no próprio âmbito da escola (o texto será publicado no jornal, no blog da escola, como pôster na parede, ou servirá para levar ao diretor/ coordenador uma reivindicação dos alunos, etc.), como pode ir para além dos muros da escola. Neste caso, alia-se a práticas comunitárias (temáticas que dizem respeito ao local onde se localiza a escola: reivindicações do bairro, coleta seletiva de lixo, etc.) ou a práticas profissionais (como inscrever-se para um concurso/emprego; carta de recomendação, o que é isto; carta de apresentação para um emprego; curriculum vitae) e até a práticas políticas (debates, encaminhamento de reivindicações, conversa com autoridades). (GUIMARÃES, 2014). 
Durante a formação continuada realizada entre 2010-2014, foram desenvolvidos, pelas professoras cursistas em parceria com os pesquisadores do Programa de PósGraduação em Linguística Aplicada da Unisinos, diferentes projetos didáticos de gênero para serem desenvolvidos em suas turmas, sendo que o corpus do presente estudo foi originado a partir do desenvolvimento de um desses projetos. A opção por voltar a esses dados deve-se à ausência de exploração desses materiais pelo grupo de pesquisa e à necessidade de se aprofundar, em novos projetos de pesquisa e interlocução com professores da Educação Básica, modos de ressignificar o trabalho com produção textual escrita no Ensino Fundamental.

Considerando que o ponto de partida de um PDG é "[...] a realidade social dos alunos, o que leva ao estudo da linguagem por meio de gêneros vinculados a uma prática social de referência” (MARQUES, 2015, p. 102), o projeto didático de gênero que deu origem às produções escritas analisadas neste artigo emergiu a partir de problemas de trânsito que ocorriam em frente à escola de uma turma de $6^{\circ}$ ano do Ensino Fundamental do município de Novo Hamburgo (RS) e que causavam riscos às crianças quando do horário de entrada e/ou saída da escola. A fim de mobilizar a turma para a produção e circulação de textos alinhados a uma prática social autêntica, a proposta do PDG em questão era de que os alunos produzissem cartas de reclamação - definindo-se, portanto, o gênero de texto - destinadas à Guarda Municipal de Novo Hamburgo com o objetivo de que o problema fosse solucionado - ou ao menos que essa problemática fosse retratada pelos alunos em suas cartas, fazendo com que sua consciência crítica e cidadania fossem aguçadas pelo trabalho com a produção textual em sala de aula - e para além dela. Além disso, o trabalho com esse gênero permitiu que fossem desenvolvidas capacidades de linguagem ligadas ao domínio de gêneros argumentativos, competências essas essenciais à interação social diante de problemas controversos ou que exijam uma tomada de posicionamento dos sujeitos neles envolvidos.

Para o planejamento das oficinas do projeto, além do diagnóstico das produções iniciais dos alunos, a professora e os pesquisadores elaboraram um modelo didático de gênero $(\mathrm{MDG})^{6}$ para estudo das características ensináveis do gênero. No MDG elaborado, descreveu-se a carta de reclamação como:

\footnotetext{
${ }^{6}$ A estrutura do planejamento das oficinas e o MDG elaborado para este PDG são mais bem descritas no trabalho de Bartholomeu (2016).
} 
[...] pertencente ao domínio do argumentar e é utilizada quando o remetente descreve um problema ocorrido a um destinatário que pode resolvê-lo. Por este motivo, quem reclama deve se utilizar de um discurso argumentativo: descreve de maneira clara o(s) problema(s), motivo(s) pelo qual pode ter ocorrido, as consequências se não for resolvido. $\mathrm{A}$ exposição dos fatos deve comprovar que o remetente é quem tem razão, o qual pode ainda, apontar as possíveis soluções para que haja entendimento entre as partes. (BARTHOLOMEU, 2016, p. 62).

Em relação ao pertencimento do gênero carta de reclamação ao domínio/agrupamento de gêneros do argumentar (SCHNEUWLY; DOLZ, 2004), cabe elucidarmos que a argumentação, apesar de ter surgido, conforme Barbisan (2007), como uma lógica científica e exata de uso da linguagem, do ponto de vista da retórica, não se restringe apenas a esse raciocínio lógico científico - isto é, de silogismo - pois ela contempla “[...] um conjunto de atos de linguagem planejados e dirigidos a um público em determinado contexto" (BARBISAN, 2007, p. 112). Portanto, argumentar também é considerar os interlocutores e seus papéis sociais, além do espaço social, político, geográfico e histórico em/para que a argumentação está sendo desenvolvida/dirigida.

De acordo com Koch (2011), compreendemos os atos de linguagem citados por Barbisan (2007) como ações no mundo que se caracterizam pela argumentatividade. Nesse sentido,

[...] a argumentação envolve um propósito sobre o mundo cuja legitimidade é questionada por alguém; um sujeito que se engaja em relação a esse questionamento e desenvolve um raciocínio para tentar estabelecer uma verdade sobre esse propósito; e um outro sujeito que constitui o alvo da argumentação. (GIERING, 2003, p. 216).

Assim, do ponto de vista do trabalho do professor de língua portuguesa, podemos afirmar que o ensino da argumentação a partir desse gênero de texto não se encerra apenas no ensino de conjunções, operadores argumentativos ou outros elementos linguísticos tradicionalmente ligados à argumentação per se, mas sim de um ensino situado e contextualizado de usos de elementos linguísticos e suas funções/implicações em determinada prática social, com determinado gênero de texto que seja adequado para a situação de referência. Logo, espera-se que o ensino de escrita de textos do gênero "carta de reclamação", como um gênero do domínio do argumentar, que proporciona o exercício da cidadania, contemple, além de aspectos estruturais e linguístico-discursivos específicos do gênero, aspectos relacionados ao propósito da ação linguageira e aos efeitos de sentido que determinados usos agregam ao texto. 
A partir das questões apresentadas até então, analisaremos o trabalho de ensino de escrita no PDG sobre carta de reclamação considerando a prática social descrita, o contexto que a circunda e a sua função argumentativa tendo em vista uma intervenção e um propósito sobre o mundo.

\section{Do papel que exerce a interação/avaliação/correção do professor na escrita discente}

Referente à interação/avaliação/correção da professora das produções textuais de seus alunos, é importante termos em vista que, em relação ao trabalho docente, de modo geral, defende-se um ideal de que o professor assuma o papel de mediador (MALENTACHI; MENEGASSI, 2006), facilitador (SUASSUNA, 2011) ou coautor (RUIZ, 1998) do texto do aluno. Para Malentachi e Menegassi (2006), o professor mediador deve questionar o texto do aluno e esse é o fator mais importante para o desenvolvimento da escrita. Segundo Suassuna (2011), o professor, ao exercer um papel de propiciador e facilitador da reflexão, deve dialogar com o texto do aluno a partir de perguntas que façam o aluno assumir uma leitura crítica acerca do próprio texto a partir da leitura/interpretação do outro, tendo em vista a situação interacional em que o texto está envolvido. Assim, ao refletir sobre o próprio texto, o aluno estará compreendendo a dimensão discursiva e ampliando sua compreensão acerca do efetivo uso de conhecimentos linguísticos.

A mediação do professor no processo de produção de texto é determinante para o desenvolvimento da escrita dos alunos, especialmente quando se desenvolve uma avaliação/correção que não considera somente aspectos gramaticais, mas que, além disso, atenta a aspectos discursivos que o gênero de texto mobiliza. Segundo Suassuna (2011, p. 120):

[...] a correção de textos escolares não é uma mera aferição do domínio de regras, mas um trabalho de negociação de sentidos. Se escrever exige ter em mente as condições em que o texto será lido para deixar no papel marcas formais que permitam ao leitor ter acesso ao conteúdo, ler, por sua vez, requer considerar as condições em que o texto foi escrito, trabalhando num processo de cooperação com o autor. Em decorrência dessa concepção, a postura prescritivista deve dar lugar a uma atitude de mediação, buscando-se analisar as falhas e as virtudes, as ideias e as formas dos textos dos alunos, em conexão com suas muitas possibilidades de leitura. 
Ruiz (1998) corrobora com tal concepção e defende, ainda, que o professor não deve ser apenas um observador do texto, mas um coautor no processo de escrita:

O professor tem que se integrar na situação de produção como coautor, e não como mero observador. É interagindo realmente com o aluno que ele pode mudar as coisas no ensino da escrita. E isso não se consegue sem um envolvimento maior com o aluno produtor, sem um compromisso pessoal com o próprio trabalho, sem uma pequena dose de afetividade. (RUIZ, 1998, p. 191).

Cumpre esclarecer que Ruiz (1998), a partir de Serafini (1989), classifica a correção indicativa como aquela em que são realizadas indicações dos erros de palavras, frases e períodos pelo professor. A correção classificatória, segunda a autora, "consiste na identificação não ambígua dos erros através de uma classificação. Em alguns desses casos, o próprio professor sugere modificações, mas é mais comum que ele proponha ao aluno que corrija sozinho o seu erro [...]” (SERAFINI, 1989 apud RUIZ, 1998, p. 45). Já na correção resolutiva, o professor busca ver no texto do aluno aquilo que não está em consonância com a norma culta da língua portuguesa e "reescreve depois tais partes fornecendo um texto correto" (RUIZ, 1998, p. 41). Por fim, Ruiz ainda destaca outro tipo de correção encontrada em suas pesquisas, que é a correção textual-interativa. Segundo a autora, esta correção caracteriza-se pela produção de "comentários mais longos [...] razão pela qual são geralmente escritos em sequência ao texto do aluno" (RUIZ, 1998, p. 47). Nesse caso, há um detalhamento maior na correção e um diálogo interativo com o aluno através de seu texto a fim de construir um texto que satisfaça a norma padrão da língua portuguesa e, a nosso ver, a adequação do texto ao gênero de texto a que pertence. Essa atividade de correção de textos se configura como trabalho real, isto é, está relacionada ao modo como a professora conduz sua proposta didática nas atividades de escrita do PDG, ainda que nem sempre essa condução seja realizada em interação face a face em sala de aula.

Sendo assim, no contexto deste estudo e a partir dos dados que analisamos, procuraremos demonstrar que a professora em questão assume os papéis que expusemos nesta seção (mediadora/facilitadora/coautora) ao avaliar/corrigir o texto do(s) aluno(s), colocando-o(s) no papel de leitor(es) reflexivo(s) a partir de sua leitura e questionamentos e, então, construindo conjuntamente os sentidos dos textos. Dessa forma, ela busca o desenvolvimento dos textos do(s) aluno(s)-autor(es) (MALENTACHI; MENEGASSI, 2006) mediante o processo de reescrita, em diálogo com as cartas de reclamação por ele(s) redigida(s). A partir dessa premissa, cabe-nos ainda observar se (e, em caso afirma- 
tivo, como) o aluno cujas produções são aqui analisadas reage textual/discursivamente à interação/avaliação da professora em seus textos.

\section{Dos procedimentos metodológicos: contexto e geração de dados}

Conforme mencionamos brevemente anteriormente, o projeto didático de gênero (PDG) que dá origem aos dados aqui analisados foi elaborado no âmbito de um curso de formação continuada destinado a professores de língua portuguesa promovido pelo projeto de pesquisa "Por uma formação continuada cooperativa para o desenvolvimento de leitura e produção textual escrita no Ensino Fundamental" (Programa Observatório da Educação/Capes - Edital 038/2010) - parceria entre o Programa de Pós-Graduação em Linguística Aplicada da Unisinos e a Secretaria Municipal de Educação de Novo Hamburgo/RS.

Produzido por uma professora atuante, à época, há 16 anos no ensino de Língua Portuguesa, formada em Letras e especialista em Literatura Brasileira do século XX aplicada aos Ensinos Fundamental e Médio, o PDG teve como objetivo que os alunos da turma se posicionassem, por meio da escrita de cartas de reclamação, sobre problemas de trânsito em frente à escola a fim de argumentar, junto à Guarda Municipal, que se fazia necessária alguma ação para solucionar a questão apresentada pelos alunos em suas cartas de reclamação.

A geração dos dados que compõem este artigo foi realizada durante o desenvolvimento do PDG sobre o gênero carta de reclamação, o qual teve 10 oficinas distribuídas em $24 \mathrm{~h} / \mathrm{a}$. Seguindo a proposta de trabalho dessa forma de organizar o trabalho pedagógico, a produção textual ocupa papel central no trabalho com PDG. Nesse sentido, os alunos foram instigados a produzir quatro versões/textos do gênero estruturante do projeto, sendo uma produção inicial, uma produção final pós-oficinas, e duas reescritas, a primeira redigida à mão, na qual a professora ainda interagiu com o texto, e uma versão final, digitada e impressa, pois esta seria a produção a ser enviada à Guarda Municipal. Todas as produções foram realizadas individualmente, em sala de aula, durante o desenvolvimento do projeto, e foram fotocopiadas pelo grupo de pesquisa, para compor o acervo do banco de dados do projeto. Analisaremos especificamente a produção final digitada e as duas reescritas de um estudante (Aluno 1), observando se as intervenções da professora e a grade de avaliação que prescreveu esse trabalho influenciam nas reescritas do texto. 
Como critério de seleção dos textos/aluno, esclarecemos que sua seleção se deve ao fato de que neles identificamos, segundo os princípios de Ruiz (1998), um número maior de ocorrências de correções textuais-interativas da professora, e não apenas correções indicativas, classificatórias ou resolutivas. Tendo em vista as recorrências de intervenções da professora, a partir da análise dos textos dos estudantes, optamos por focar no desenvolvimento da produção textual de um deles, pois apresenta mais evidências (e de modo mais compreensível nas fotocópias) de intervenções textuais-interativas da professora e permite ilustrar a discussão aqui proposta sobre o impacto do trabalho docente na aprendizagem discente da escrita. Cabe ressaltar que, para este estudo, não contemplamos as orientações ocorridas entre a professora e os alunos em sala de aula, pois não tivemos acesso a essa dimensão do trabalho real da professora. Ainda, como mencionado na introdução deste texto, a opção pelo estudo de caso decorre do fato de que queremos elucidar com mais profundidade o impacto do trabalho docente na produção escrita discente, considerando, especialmente, que se trata de um trabalho de ensino não controlado pelos pesquisadores, mas sim de uma análise explicativa do fenômeno observado.

Em termos analíticos, nossas categorias contemplam, neste artigo, além da classificação dos tipos de correção previamente citados, a identificação do(s) tipo(s) de discurso empregado(s) pela professora, com base em Bronckart (1999), em interação assíncrona com os estudantes no momento de correção, a fim de verificar se ela os instiga a desenvolverem os textos atentando ao seu caráter genérico/de genericidade. Tendo em vista que o agir linguageiro da professora pode ser conjunto ou disjunto ao mundo ordinário, então verificaremos se ela se implica (discurso interativo) ou não (discurso teórico) ao intervir nos textos do aluno e se essas intervenções influenciam no desenvolvimento das produções textuais. A produção inicial do estudante não será analisada porque não fornece dados para este estudo, uma vez que foi utilizada para diagnosticar a escrita dos estudantes quanto ao domínio do gênero carta de reclamação e os textos produzidos não apresentam intervenções escritas da professora.

\section{Dos conhecimentos evidenciados sobre o gênero de texto "carta de reclamação" na produção textual}

Conforme mencionado anteriormente, iniciamos esta análise verificando as produções do Aluno 1, como podemos observar a seguir. 
Figura 1 - A produção final manuscrita.

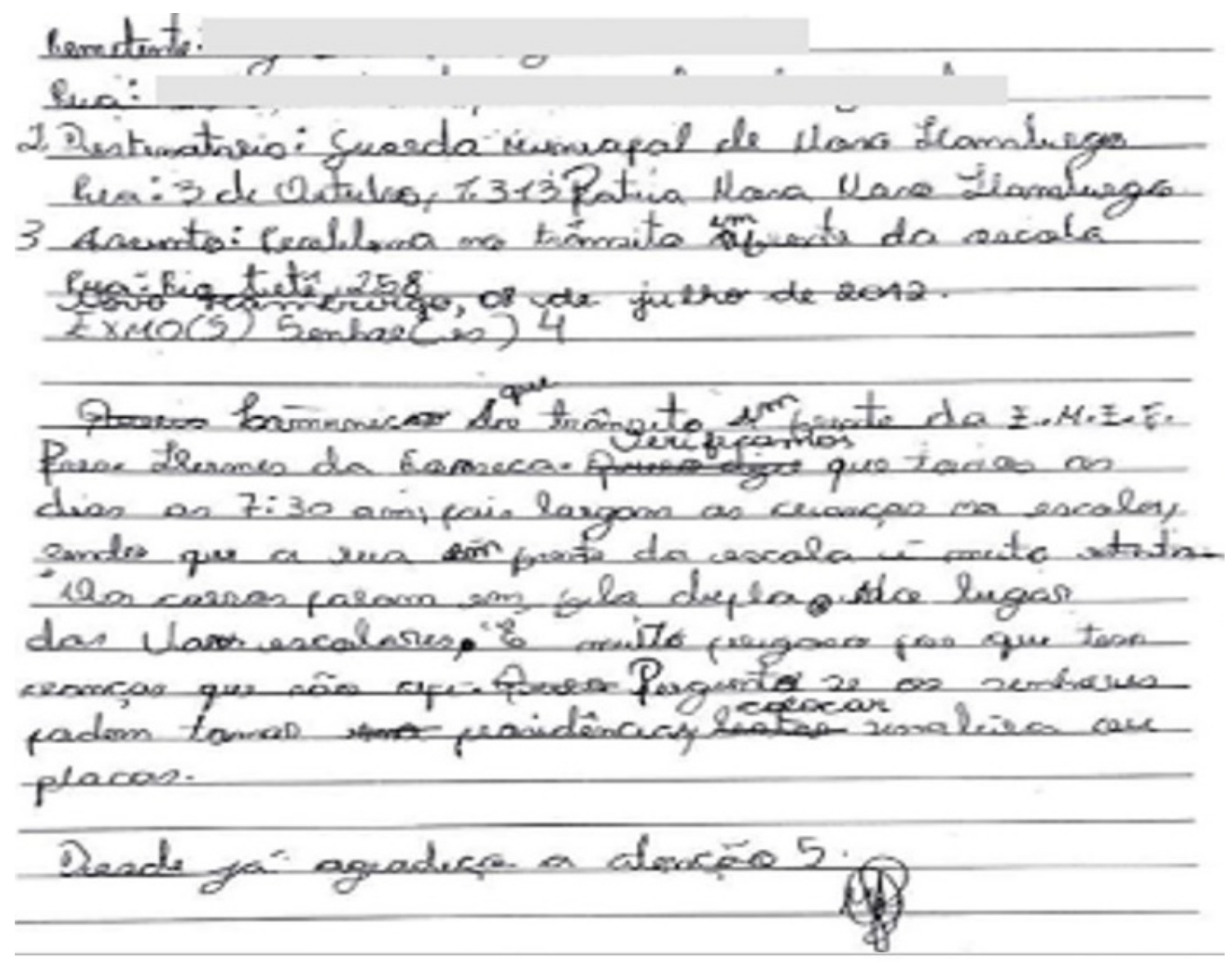

Fonte: Acervo do Projeto "Por uma formação continuada cooperativa para o desenvolvimento de leitura e produção textual escrita no Ensino Fundamental”.

Nessa produção, o aluno demonstra ter se apropriado satisfatoriamente do gênero de texto trabalhado (carta de reclamação), evidenciando compreensão da prática social (interação com autoridades responsáveis pelo trânsito) e da finalidade argumentativa almejada (convencer a Guarda Municipal sobre um problema de trânsito em frente à escola), dos interlocutores envolvidos (autoridade representada pela Guarda Municipal), do conteúdo temático (reclamação sobre o problema que afeta a comunidade escolar) e da estrutura da carta de reclamação, dentre outros aspectos. Ao focarmos nossa análise na correção da professora, percebemos que se destaca a correção resolutiva acerca de questões que envolvem regência, pontuação e ortografia. $O$ texto do Aluno 1 apresenta um problema referente à estrutura do gênero e a professora faz uma correção resolutiva ao redigir corretamente como se insere a cidade da pessoa remetente e a data em que a carta foi redigida. 
Observamos que, devido ao desenvolvimento de um PDG sobre o gênero carta de reclamação, em que várias oficinas dedicaram-se às características desse gênero, o estudante demonstra ter se apropriado de diversas características relacionadas tanto ao estilo, quanto ao conteúdo temático e à estrutura composicional desse gênero, mas ainda possui certas dificuldades, principalmente com alguns elementos constitutivos do plano de texto. Para adensarmos nossas reflexões sobre isso, na seção seguinte, analisaremos com mais profundidade o desenvolvimento da produção textual do "Aluno 1", tendo em vista as intervenções assíncronas da professora e as características do gênero "carta de reclamação".

\subsection{O processo de desenvolvimento da escrita do Aluno 1}

Nesta seção do artigo, investigaremos como a professora conduziu um dos estudantes à reescrita e à versão final, considerando também a grade de avaliação que prescreveu esta proposta, a fim de verificar se houve desenvolvimento do texto do Aluno 1, principalmente no que se refere à habilidade de argumentação, constitutiva do gênero trabalhado.

Figura 2 - Reescrita e versão final do Aluno 1.

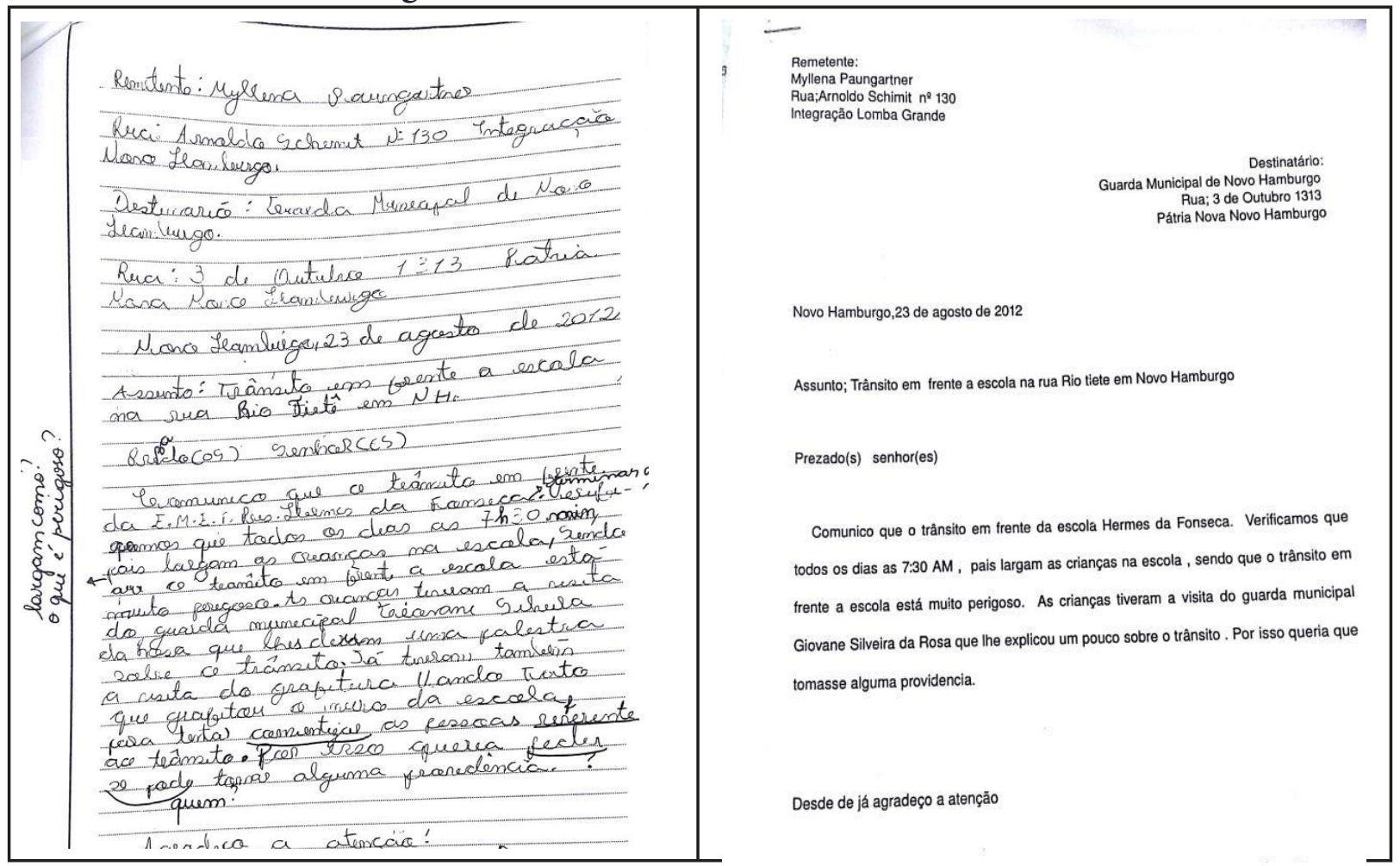

Fonte: Acervo do Projeto "Por uma formação continuada cooperativa para o desenvolvimento de leitura e produção textual escrita no Ensino Fundamental”. 
Na produção final, percebemos que a professora ainda indica alguns problemas referentes à ortografia e faz uma correção resolutiva na escrita do adjetivo "prezado", sendo que o Aluno 1 faz algumas modificações (nem todas) na versão final. Apesar de ortografia ser uma questão que deve ser ensinada e corrigida em qualquer gênero de texto, não exclusivamente na carta de reclamação, a dificuldade do estudante com a escrita do adjetivo "prezado" torna-se mais evidente nessa produção/gênero, pois, possivelmente, em outras produções escolares (ou para além da escola) essa não seja uma unidade lexical recorrentemente presente nas práticas de escrita do Aluno 1. Desse modo, reitera-se a importância de diversificar o trabalho com diferentes gêneros de texto na escola, possibilitando aos alunos a aprendizagens de, dentre outras coisas, novas formas de utilizar a língua(gem) e de suas unidades constitutivas, nas mais distintas dimensões.

Há, especialmente na produção final manuscrita, correções textuais-interativas em relação à coerência do texto, em que identificamos o discurso interativo (BRONCKART, 1999), pois a professora utiliza frases interrogativas e verbos no presente do indicativo e infinitivo ("largam como?”, “o que é perigoso?”, “terminar”) estabelecendo uma interação assíncrona com o estudante, a fim de que ela retome o texto e preencha as lacunas para melhor entendimento de quem receberá e fará a leitura da carta. Entendemos que, dessa forma, ao indagar sobre as lacunas do texto, a professora está assumindo seu papel de mediadora da produção textual e instigando o estudante a retornar para o próprio texto como um leitor crítico e reflexivo. Considerando que “[...] uma correção dessa ordem amplia o universo de conhecimentos linguísticos do aluno e, por isso, abre a possibilidade de performances escritas mais satisfatórias" (RUIZ, 1998, p. 192), ao propor as reescritas, essa professora se envolve no processo de desenvolvimento do texto do aluno como uma coautora facilitadora (SUASSUNA, 2011; RUIZ, 1998) que busca construir os sentidos do texto em parceria com o discente e não ser apenas uma observadora externa que avalia apenas para atribuir nota.

Bronckart (1999, p. 237) define as sequências que a professora indica como lacunas no texto do aluno como "[...] modalidades particulares de planificação do conteúdo temático, baseadas em operações de caráter dialógico". Ou seja, ao realizar correções como as identificadas nesse texto e também ao ensinar o gênero de texto inserindo remetentes reais, a professora ensina ao aluno (e à turma em geral) que o texto possui um objetivo no mundo e, portanto, será lido por uma autoridade da Guarda Municipal que poderia resolver o problema, isto é, estabelecendo uma prática de interlocução autêntica. 
Para nossa análise, é importante também considerarmos a prescrição pela qual tanto a turma quanto a professora se basearam para a avaliação das produções textuais: a grade de avaliação empregada durante o desenvolvimento do projeto didático de gênero sobre carta de reclamação. Apresentamos a seguir a grade de avaliação empregada pelo Aluno 1 para a autoavaliação de sua produção textual, bem como a interlocução da professora com esse instrumento e com seu estudante.

Figura 3 - A grade de avaliação.

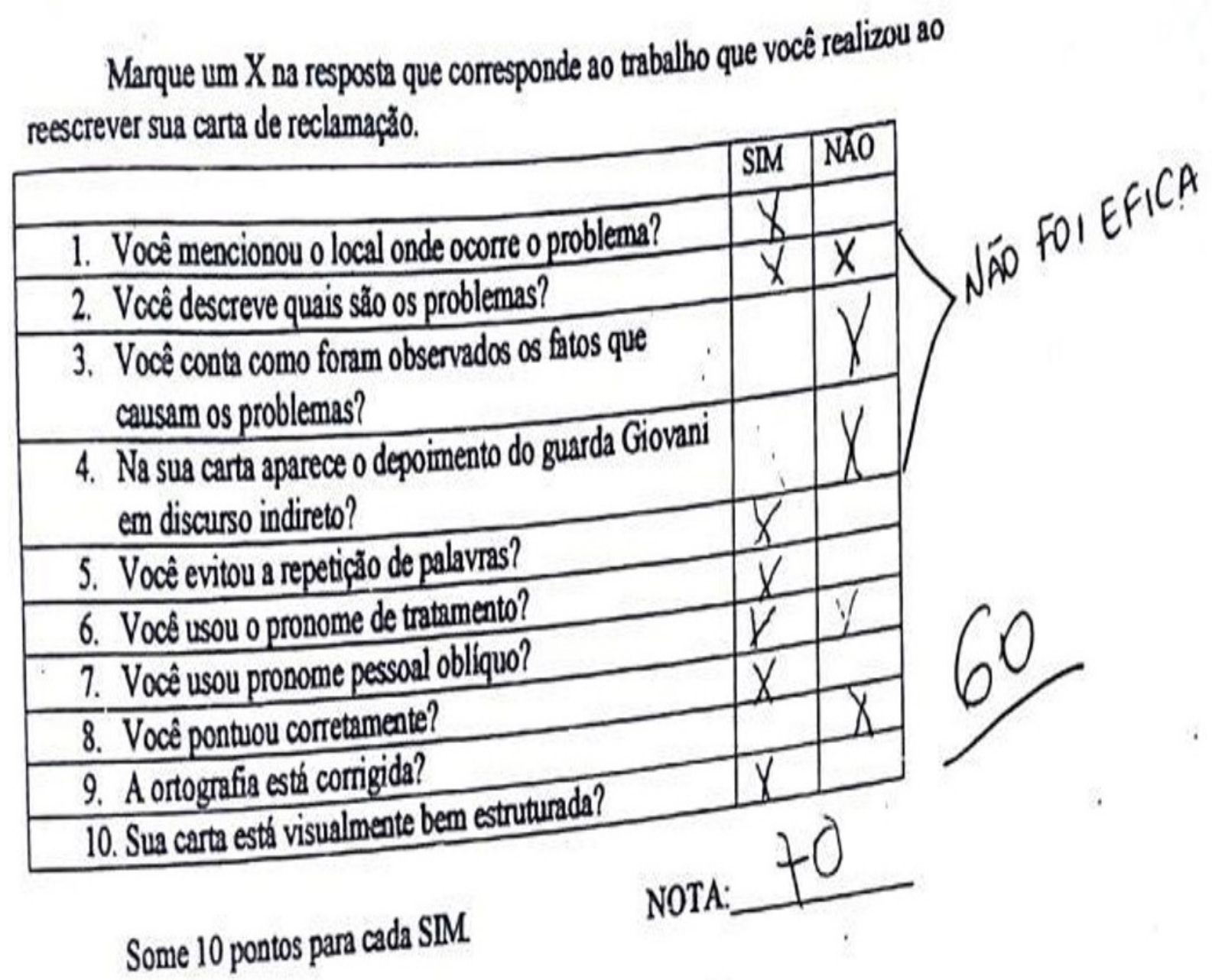

Fonte: Acervo do Projeto "Por uma formação continuada cooperativa para o desenvolvimento de leitura e produção textual escrita no Ensino Fundamental”.

O Aluno 1 demonstra que se apropriou da estrutura visual ${ }^{7}$ do gênero, porém ainda não demonstra clareza sobre sua organização textual, seu caráter dialógico e seu objetivo como prática social, indicando que ainda precisa desenvolver habilidades melhores de es-

\footnotetext{
${ }^{7}$ Chamamos de estrutura visual a organização gráfica do gênero de texto, cf. Reuter (2013).
} 
crita do gênero, principalmente referentes à argumentação. Nesse sentido, é interessante observar como o estudante percebe que não cumpriu alguns requisitos do gênero (itens 3 e 4) ao fazer sua autoavaliação, tanto que a nota atribuída por ele ao próprio texto se aproxima muito da nota atribuída pela professora. Dessa forma, ele indica que reconhece algumas lacunas, porém não as desenvolve, provavelmente por não saber como fazê-lo, evidenciando ainda mais a importância do papel mediador do professor no desenvolvimento de competências de escrita dos estudantes.

Referente ao processo de desenvolvimento da produção textual do Aluno 1, notamos que, da produção final para a reescrita e, finalmente, para a versão final, houve modificações no conteúdo temático e na infraestrutura da carta.

Figura 4 - Comparação entre produção final, reescrita e versão final.

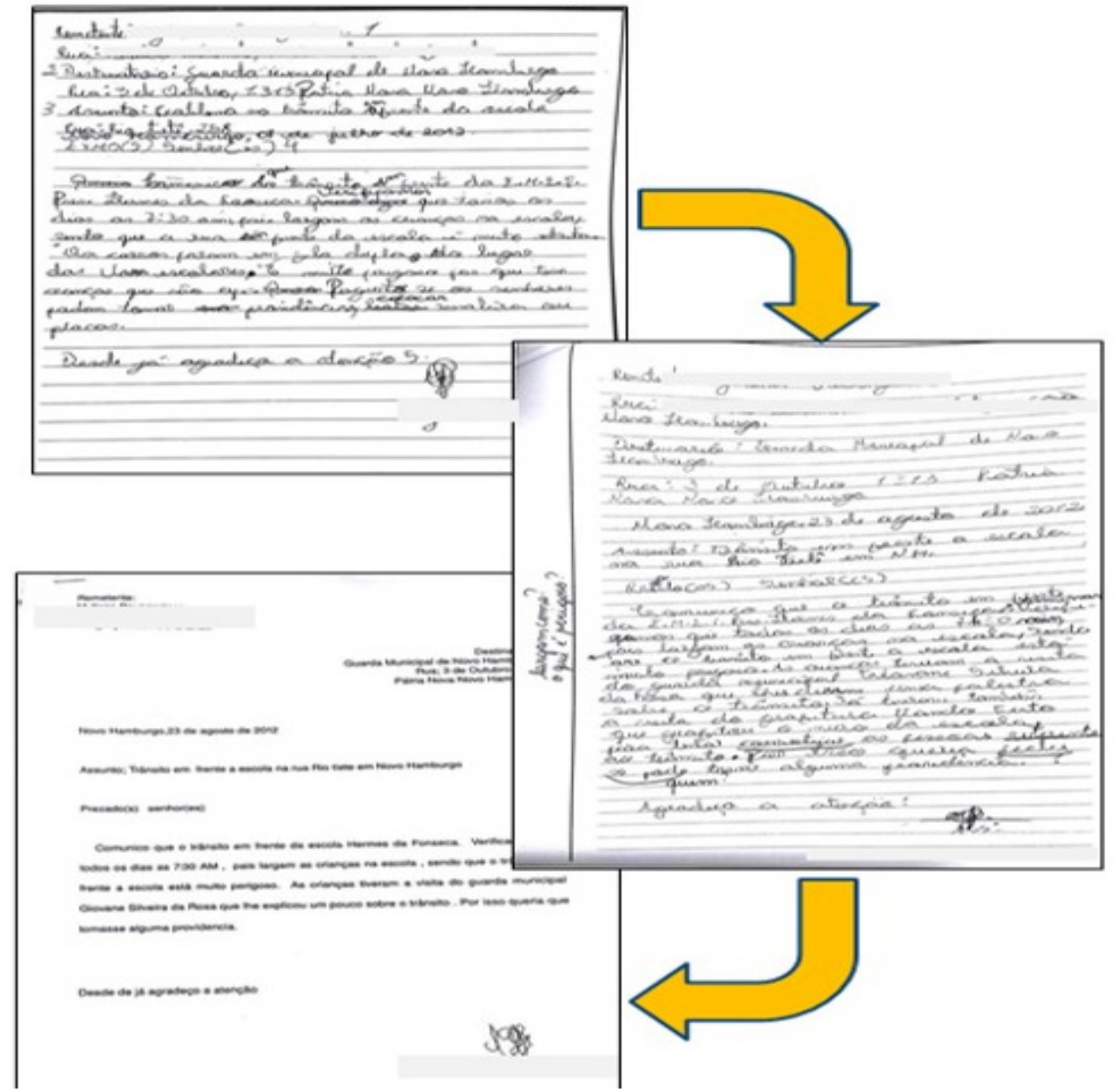

Fonte: Elaborada pelos autores a partir do acervo do projeto "Por uma formação continuada cooperativa para o desenvolvimento de leitura e produção textual escrita no Ensino Fundamental”. 
$\mathrm{N}$ o

que concerne à estrutura visual, é aparente que houve

desenvolvimento e adequação ao gênero. Referente à infraestrutura interna do texto, porém, notamos que o aluno enfraquece seu projeto argumentativo. Na tabela abaixo, transcrevemos esse processo exatamente com as palavras do estudante em seus textos:

Tabela 1 - O desenvolvimento do conteúdo temático.

\begin{tabular}{|c|c|c|}
\hline Produção Final & Reescrita & Versão Final \\
\hline $\begin{array}{l}\text { Quero dizer que todos os } \\
\text { dias as } 7: 30 \text { am, pais lar- } \\
\text { gam as crianças na escola, } \\
\text { sendo que a rua em frente } \\
\text { da escola é muito estreita. } \\
\text { Os carros param em fila } \\
\text { dupla, no lugar das vans } \\
\text { escolares. É muito peri- } \\
\text { goso por que tem crianças } \\
\text { que vão apé. }\end{array}$ & $\begin{array}{l}\text { Verificamos que todos os } \\
\text { dias as } 7 \text { h30min pais lar- } \\
\text { gam as crianças na escola, } \\
\text { sendo que o trânsito em } \\
\text { frente a escola está muito } \\
\text { perigoso. As crianças ti- } \\
\text { veram a visita do Guarda } \\
\text { municipal [nome do guar- } \\
\text { da] que lhes deu uma pa- } \\
\text { lestra sobre o trânsito. Já } \\
\text { tiveram também a visita } \\
\text { do grafiteiro [nome do } \\
\text { grafiteiro] que grafitou o } \\
\text { muro da escola para tentar } \\
\text { conscientizar as pessoas } \\
\text { referente ao trânsito. }\end{array}$ & $\begin{array}{l}\text { Verificamos que todos } \\
\text { os dias as 7:30 AM, } \\
\text { pais largam as crianças } \\
\text { na escola, sendo que } \\
\text { o trânsito em frente a } \\
\text { escola está muito peri- } \\
\text { goso. As crianças tive- } \\
\text { ram a visita do Guarda } \\
\text { municipal [nome do } \\
\text { guarda] que lhes expli- } \\
\text { cou um pouco sobre o } \\
\text { trânsito. }\end{array}$ \\
\hline
\end{tabular}

Fonte: Elaborada pelos autores a partir dos textos do Aluno 1.

Os argumentos presentes na produção final são modificados na reescrita e, posteriormente, descartados na versão final. Na produção final, o Aluno 1 descreveu o problema e, na reescrita, por sua vez, ele mencionava o fato de que já havia sido realizada uma ação de conscientização que não foi suficiente (o grafite dos muros da escola), um forte argumento de que a ação da Guarda Municipal, como autoridade que teria poder e recursos para solucionar a questão, seria importante e necessária, já que ações locais não resolveram o problema. 
Em vez de manter tais argumentos, da produção final ou da reescrita, ele utiliza, na versão final, apenas o argumento de que a turma recebeu orientações de um guarda municipal e, simplesmente por isso, ele queria que tomassem providências. Nesse sentido, o texto perdeu força argumentativa, uma vez que "[...] a exposição dos fatos deve comprovar que o remetente é quem tem razão" (MARQUES, 2015, p. 99) e o estudante está transferindo seus argumentos que descrevem o problema para o fato de que um profissional com mais conhecimento sobre o fato fez uma visita à turma, mas não explica o que a turma aprendeu com este profissional. Portanto, em seu texto, ele está transferindo seus argumentos para a figura do guarda, como autoridade, e perde sua exposição de fatos que comprovam que o problema precisa ser solucionado, mantendo apenas a afirmação de que o trânsito "está muito perigoso", não descrevendo este "perigo", isto é, a versão final não faz o destinatário "ver" o problema. Aparentemente, não ficou claro para o estudante que a professora, ao trabalhar com as características do gênero carta de reclamação, pedia a inserção do discurso desse guarda e também uma descrição do problema e dos fatos que os causam.

Retomando Bartholomeu (2016, p. 92), é possível considerar que o Aluno 1 não está fazendo "descrição, de maneira clara, do(s) problema(s) e de suas possíveis causas", portanto, o agir linguageiro praticado pode não ter o efeito pretendido, uma vez que faltam ao texto sequências que convençam o leitor de que o problema de trânsito é grave e precisa ser resolvido (sequência argumentativa), utilizando, para isso, operações que visam a resolver esse problema (sequência explicativa) fazendo com que o leitor o "veja" (sequência descritiva) a partir do texto. Assim, identificamos problemas em relação à arquitetura textual, tanto no nível da infraestrutura da arquitetura textual (plano do texto e eventuais sequências), quanto nos mecanismos de textualização (referentes à coerência do texto) e de responsabilidade enunciativa, considerando que o aluno se abstém de expor seus argumentos pessoais ao optar por transferi-los a uma figura de autoridade de modo muito breve - e que não é eficaz na tarefa de elucidar sobre o problema.

Além disso, é interessante observar como o estudante altera a modalização empregada ao sugerir “[...] soluções para que haja entendimento entre as partes", uma vez que, na produção final anterior, ele finaliza seu texto com uma pergunta ("pergunto se os senhores podem tomar providências, botar sinaleira ou placas"), o que demonstra incerteza quanto ao fato de que o(s) destinatário(s) da carta seja(m) quem pode solucionar o problema. Na versão final, ele muda a sua frase para uma declarativa "por isso, queria que tomasse alguma providência”, mas retira suas sugestões. Assim, a mudança de uma frase interrogativa para uma frase assertiva já dá indícios de desenvolvimento do texto em relação ao seu objetivo de convencer. 
Diante do que observamos no processo de produção textual deste aluno, percebemos que a grade de avaliação, como prescrição/orientação para o trabalho de (re)escrita, possui maior grau de influência na produção escrita do estudante que o trabalho real (assíncrono) de correção textual-interativa, isto é, as intervenções escritas da professora, fortemente caracterizadas pelo uso de discurso interativo, pouco influenciaram no desenvolvimento/reescrita dos textos. As correções indicativas e resolutivas possuem um maior índice de intervenção no trabalho, o que indica que o aluno possui maior dificuldade com a produção textual em si e não com regras gramaticais exploradas pela professora - as quais, inclusive, não dependem diretamente da organização textual para serem avaliadas/ corrigidas. Da reescrita para a versão final, por exemplo, apesar de ter realizado ajustes de regência e ortografia, o aluno não desenvolveu nada que a professora demonstrou como problema, no nível dos mecanismos de textualização, na correção. $\mathrm{O}$ abandono de argumentos pelo estudante parece estar relacionado a uma falta de clareza relacionada aos itens (2), (3) e (4) da grade de avaliação, pois a professora pede uma descrição do problema, como ele foi observado e a inserção do depoimento do Guarda Municipal que visitou a turma com discurso indireto, mas o aluno, em seu texto, não soube articular esses itens de forma coerente, a favor de sua reclamação/solicitação, conforme a professora indica na grade de avaliação ("não foi eficaz").

O trabalho com a escrita no âmbito de um PDG se encerra na versão final do texto, porém, considerando que a carta de reclamação é um texto argumentativo e a escrita do estudante não foi suficientemente eficaz ao expor os argumentos na versão final, entendemos que o trabalho com este gênero e suas características ainda não está concluído. É preciso que, em outros momentos de seu processo de escolarização, outras propostas de produção de texto voltem a abordar características inerentes a gêneros do domínio do argumentar, a fim de ampliar suas competências linguístico-textual-discursivas na produção de gêneros de texto desse domínio.

\section{Considerações Finais}

O trabalho com gêneros de texto em sala de aula favorece o ensino de linguagem como interação, promovendo a produção de textos que levem em consideração suas diferentes dimensões, sempre relacionados a práticas sociais autênticas. Consoante a isso, é de extrema importância que os alunos sejam educados para, dentre outras coisas, serem capazes de interagir com as mais diversas situações reais da vida em que argumentar seja uma necessidade real - e não apenas para provas escolares ou para a escrita de redações produzidas com a mera finalidade de atribuir uma nota. 
No âmbito deste artigo, cujo foco recaiu sobre os traços de desenvolvimento da escrita, especificamente da argumentação, na produção do gênero carta de reclamação por um estudante do Ensino Fundamental, bem como na análise sobre como o trabalho docente impacta nesse desenvolvimento, a partir das correções desenvolvidas pela professora nas produções textuais de um discente, pudemos produzir algumas asserções as quais queremos apresentar agora, a propósito de considerações finais deste texto.

Durante o processo de desenvolvimento das produções textuais dos estudantes, é muito importante que o professor tenha clareza sobre sua metodologia de ensino, consciência sobre o seu papel central como mediador da aprendizagem da escrita e de que sua maneira de intervir nos textos dos alunos pode ser um grande aliado no desenvolvimento das competências de escrita dos estudantes. Dito de outro modo, gostaríamos de realçar que o modo como o professor planeja a atividade de produção escrita (tomando as noções de gênero de texto e de prática social como norteadoras de seu trabalho) e o modo como avalia/corrige os textos de seus alunos influencia diretamente no desenvolvimento destes. As correções resolutivas e indicativas, por exemplo, são mais objetivas em relação ao que se espera que os estudantes ajustem em seus textos, sendo, por isso, as que mais interferem em processos de reescrita, especialmente no contexto desta pesquisa. As correções textuais-interativas, porém, exigem maior reflexão por parte dos estudantes, elevando o grau de dificuldade da atividade, o que exige do professor um acompanhamento mais intenso e próximo dos alunos - ou suas intervenções podem ser desconsideradas, muitas vezes, pela falta de compreensão dos alunos sobre o que precisa ser realizado e como fazê-lo.

Considerando que, durante a produção (e mesmo a avaliação/correção) dos textos, é importante que o professor evidencie que as produções terão uma função interacional no mundo, nossa análise sugere que as correções textuais-interativas indicaram lacunas nos textos do aluno em relação ao caráter dialógico da escrita, mas essas correções tendem potencialmente a serem desconsideradas durante a reescrita - possivelmente pela dificuldade do estudante (e aqui podemos supor que dos demais estudantes da classe também) em lidar com elas. Reiteramos que esse tipo de correção é muito importante no processo de aprendizagem/desenvolvimento da escrita quando se trabalha com projetos didáticos de gênero, mas apenas a correção pode não surtir o efeito desejado nos textos dos alunos: ela precisa estar articulada à grade de avaliação e à mediação do professor em sala de aula. 
A grade de avaliação, por sua vez, mostrou-se como um instrumento importante, tanto para o professor (no âmbito das (auto)prescrições que ele produz por si e para si) quanto para esclarecer aos alunos quais os critérios adotados para avaliação/correção de suas produções textuais. Entretanto, tendo em vista que, como qualquer prescrição, ela pode restringir a compreensão dos alunos a uma sequência de tarefas a serem realizadas dentro de um texto, reduzindo sua dimensão dialógica, é importante deixar claro que os estudantes não devem perder de vista a prática social da produção de texto, talvez inserindo essa questão na própria grade de avaliação. Aliado a isso, seja através das oficinas ou das intervenções do professor na correção dos textos, é importante salientar sempre que as produções terão uma função no mundo e, para isso, devem estar organizadas de modo a considerar um gênero de texto indexado socialmente, além de projetar um leitor real, inserido em um contexto sócio-histórico específico. Certamente, este texto não responde a todas as questões que se ligam ao domínio empírico do ensino da produção textual escrita na escola, mas colabora com o campo ao reafirmar alguns princípios consolidados na literatura da área sobre avaliação da produção textual, articulando-os a um contexto específico: o ensino de língua portuguesa/produção textual escrita a partir de projetos didáticos de gênero e ao trabalho do professor à luz do ISD. Os limites deste estudo e do corpus aqui analisado nos impulsionam a seguir investigando nesse campo, com vistas a adensar as reflexões aqui apresentadas.

\section{Referências}

BAKHTIN, M. Estética da criação verbal. 4. ed. São Paulo: Martins Fontes, 2003.

BARBISAN, L. B. Uma proposta para o ensino da argumentação. Letras de Hoje, Porto Alegre, v. 42, n. 2, p. 111-138, 2007.

BARBOSA, J. P. Do professor suposto pelos PCNs ao professor real de Língua Portuguesa: são os PCNs praticáveis? In: ROJO. R. H. R. (Org.). A prática da linguagem em sala de aula: praticando os PCn's. Campinas, SP: Mercado das Letras, 2000. p. 149-181.

BARTHOLOMEU, I. C. S. Projeto didático de gênero: um estudo a partir do modelo didático de gênero e das capacidades de linguagem mobilizadas em trabalhos com cartas de reclamação. Dissertação (Mestrado em Linguística Aplicada). UFMG, Belo Horizonte, 2016.

BRASIL. Ministério da Educação e Cultura. Base Nacional Comum Curricular. Brasília, DF, 2018.

BRASIL. Ministério da Educação e Cultura. Parâmetros Curriculares Nacionais: Língua Portuguesa. Brasília, DF, 1998. 
BRONCKART, J. P. Atividade de linguagem, discurso e desenvolvimento humano. Campinas: Mercado de Letras, 2006.

BRONCKART, J. P. Atividade de linguagem, textos e discursos: por um interacionismo sócio-discursivo. São Paulo: EDUC, 1999.

BRONCKART, J. P. O agir nos discursos: das concepções teóricas às concepções dos trabalhadores. Campinas: Mercado de Letras, 2008.

DOLZ, J; GAGNON, R; DECÂNDIO, F. Produção escrita e dificuldades de aprendizagem. Campinas, SP: Mercado de Letras, 2010.

GIERING, M. E. Orientações para o trabalho com argumentação escrita na escola numa perspectiva semiolinguística. Letras de Hoje, Porto Alegre, v. 39, n 3, p. 215-225, 2003.

GUIMARÃES, A. M. M. Formação de professores: entre o acadêmico e o profissional. Palestra apresentada no $2^{\circ}$ Encontro Procad/Casadinho UFMG-UNISINOS, Belo Horizonte, 2014.

GUIMARÃES, A. M. M.; CARNIN, A.; KERSCH, D. F. (Org.). Caminhos da construção: reflexões sobre projetos didáticos de gênero. Campinas: Mercado de Letras, 2015.

GUIMARÃES, A. M. M.; KERSCH, D. F. (Org.). Caminhos da construção: projetos didáticos de gênero na sala de aula de língua portuguesa. Campinas: Mercado de Letras, 2012.

GUIMARÃES, A. M. M.; KERSCH, D. F. (Org.). Caminhos da construção: projetos didáticos de gênero no domínio do argumentar. Campinas: Mercado de Letras, 2014.

JORDÃO, H. G.; NONATO, S. Forma escolar, trabalho docente e produção textual: novas configurações. Diálogo das Letras, Pau dos Ferros, v. 7, n. 3, p. 208 - 227, set./dez. 2018.

KLEIMAN, A. B. O processo de aculturação pela escrita: ensino da forma ou aprendizagem da função? In: KLEIMAN, A.B.; SIGNORINI, I. (Org.). O ensino e a formação do professor: alfabetização de jovens e adultos. Porto Alegre: Artmed, 2000. p. 223-243.

KOCH, I. G. V. Argumentação e linguagem. 13. ed. São Paulo: Cortez, 2011.

MALENTACHI, D. A.; MENEGASSI, R. J. A mediação do professor e a participação do aluno na produção de textos. In: Congresso Latino-Americano sobre Formação de Professores de Linguas (I CLAFPL), Anais... Universidade Federal de Santa Catarina: UFSC, 2006. p. 657-671.

MARQUES, R. G. Argumentar ou não argumentar no ensino fundamental, eis a questão! In: GUIMARÃES, A. M. M.; CARNIN, A.; KERSCH, D. F. (Org.). Caminhos da construção: reflexões sobre projetos didáticos de gênero. Campinas: Mercado de Letras, 2015. p. 92-112.

PEREIRA, L. Á.; CARDOSO, I. (Coord.). Reflexão sobre a escrita: o ensino de diferentes géneros de textos. Aveiro: Editora da Universidade de Aveiro, 2013. 
PEREIRA, M. L. S.; BEZERRA, B. O Processo de reescrita no ensino do gênero carta de reclamação. Revista Leia Escola, v. 18, p. 116-131, 2018.

REUTER, Y. Statut et usages de la notion de genre en didactique(s): retour sur quelques propositions. Pratiques, Paris, n. 157/158, p. 153-164, juin. 2013.

RIO GRANDE DO SUL. Referenciais curriculares do estado do Rio Grande do Sul: linguagens, códigos e suas tecnologias/Secretaria de Estado da Educação. Porto Alegre: SE/DP, 2009.

RUIZ, E. M. S. D. Como se corrige redação na escola. Tese (Doutorado em Linguística). UNICAMP, Campinas, 1998.

SCHNEUWLY, B; DOLZ, J. Gêneros orais e escritos na escola. Tradução e Organização de Roxane Rojo e Glaís Sales Cordeiro. Campinas, SP: Mercado de Letras, 2004.

SUASSUNA, L. Avaliação e reescrita de textos escolares: a mediação do professor. In: ELIAS, V. M. (Org.). Ensino de língua portuguesa: oralidade, escrita, leitura. São Paulo: Contexto, 2011.p. 119-134.

TINOCO, G. A. Mundos de letramento de professores em formação no agreste riograndense. In: OLIVEIRA, M. S.; KLEIMAN, A. Letramentos múltiplos: agentes, práticas, representações. Natal: EDUFRN, 2008. p. 63-89. 